\title{
A Survey of Undergraduate Teaching of Child and Adolescent Psychiatry in the United Kingdom
}

DAvid CotTrell, Senior Registrar in Child Psychiatry, St George's Hospital, London SW17

Child and adolescent psychiatry is a relatively new subspeciality and it is only recently that its practitioners have started to examine the problems of teaching it on the undergraduate curriculum. Questions about when it is best taught during the undergraduate years and what constitutes a core curriculum are still contentious. Indeed some psychiatrists have yet to be convinced that it should be taught at all at an undergraduate level.

If child psychiatry is to recruit from the ranks of the best medical students, and if future general practitioners are to be prepared realistically for their likely workloads, then it seems logical that child and adolescent psychiatry should have a significant place in the undergraduate curriculum. This article presents the results of a survey of all the UK medical schools carrier out to assess the current status of undergraduate child and adolescent psychiatry teaching.

\section{The Study}

A questionnaire was sent to all the medical schools in the United Kingdom during the latter half of 1985 asking for information about child and adolescent psychiatry teaching. Questionnaires were sent either to the doctor responsible for student teaching or, where this was not known, to the head of the psychiatry department with a request to forward them to the appropriate person. A wide variation in teaching practice was expected. Therefore the questionnaire was composed of open questions concerning the general format of the teaching and more specific closed questions to elicit particular facts. Respondents were invited to append any extra information which they thought might be helpful, e.g. seminar programmes.

In six cases the information on the returned questionnaire was unclear in certain particulars. Follow-up telephone calls were made to these respondents for clarification.

Replies were received from all but one medical school, i.e. 28 replies. Approximately half of the schools needed reminders and one fifth second reminders. In all, it took approximately nine months to receive all the replies. About half of the schools returned extra information with the questionnaire. There would appear to be such diversity in the methods of teaching child psychiatry that a presentation which did justice to all would have to go through each school and describe its methods. The following account, of necessity, concentrates on those areas where comparison is possible.

\section{(1) Pre-clinical teaching}

Although pre-clinical teaching relevant to child psychiatry was specifically asked about, only 14/28 schools mentioned it in their replies. Of these, 11/14 recognised some elements of the pre-clinical curriculum as being relevant to child psychiatry. In six schools this was some form of psychology/ developmental psychology and in a further five schools sociology was added to this. Only 5/14 schools gave details of the time available. Average time was $\mathbf{9 . 2}$ hours (Range 2-22 hours).

\section{(2) Clinical teaching}

(a) Numbers and setting. There was a great variety in the structure of the clinical years of training and of the numbers of students involved. The mean number of students per year was 140 but with a range of 96-150. The mean number of students learning child psychiatry at any one time was 21 (range 4-50). Many imaginative ways have been found to accommodate the teaching, nearly always within time allocated to other disciplines. At some schools large firms of students are divided and taught on different sites or rotate through one child psychiatry placement during the course of another firm.

Eleven schools taught child psychiatry mainly during paediatrics, nine mainly during psychiatry and seven equally in both. One school teaches child psychiatry in a block designated psychosocial medicine. Although 18 schools do some teaching during the paediatric firm only six made specific mention of joint teaching with paediatricians.

Most schools (17/28) try and arrange visits to other settings, e.g. children's homes, schools, assessment centres etc. A number of schools offer extra experience to certain students, e.g. attendance at out-patient clinics may continue after the official child psychiatry placement ends. At three schools a few students may elect to spend more time in child psychiatry at the expense of adult psychiatry. Nearly all the schools offer the possibility of electives in child psychiatry and at one school 6-9 students each year take up this offer. One school offers the possibility of undergraduate students engaging in their own, supervised child psychiatry research project.

(b) Time and staffing. Tables I and II show the amount of time given over to child psychiatry. Different schools described their teaching in different ways but for the purposes of this evaluation a 'session' was counted as three hours and a 'lecture' or 'seminar' as one hour. At some schools the teaching time varied with some students able to take advantage of additional teaching. The figures in Tables I and II represent the maximum number of hours available to all students.

All 5 of the schools with more than 30 hours are inside London; 6/7 schools with less than 10 hours are outside 
TABLE I

Time available for clinical teaching of child psychiatry

\begin{tabular}{lll}
\hline & Mean & Range \\
\hline Overall total (hours) & 20.4 & $5-52$ \\
London only & 28.5 & $9-52$ \\
Rest of UK & 15.2 & $5-27$ \\
\hline
\end{tabular}

TABLE II

Division of time available for child psychiatry teaching

\begin{tabular}{lrc}
\hline & Mean & Range \\
\hline Time for teaching theory & 9.4 & $3-22$ \\
Time for teaching practical skills & 12.8 & $0-33$ \\
$\%$ time for teaching theory & 46.2 & $12.5-100$ \\
\hline
\end{tabular}

NB Figures only available for $19 / 28$ schools.

London. Many of the teaching programmes were in the process of change. Interestingly, 15 schools felt able to increase teaching time without any staffing increase and $8 / 12$ schools that were increasing teaching time were doing so with no extra staff. Surprisingly, it was not always the schools with least total time that were planning such an increase.

A wide range of staff were involved in teaching. Numbers of medical staff varied from one consultant only at one school, through to six consultants plus academic staff plus junior staff at another. Only 9/28 schools had academic staff involved in teaching and these schools were not more likely to have greater teaching time.

Non-medical professions were involved in teaching at nearly every school, usually social workers and clinical psychologists but educational psychologists, occupational therapists, psychotherapists and nurses were also occasionally involved.

(c) Aims of teaching. Only 16/28 schools had clearly formulated and laid out teaching aims. Five schools had vague aims and seven had none or replied only "to teach child psychiatry". In only $11 / 28$ cases were these aims officially recognised or accepted by the medical school. Unfortunately there was no significant association of clearly formulated aims and official recognition. The stated aims could be broadly divided into the categories laid out in Table III.

(d) Teaching theory. A number of different methods were used to teach theoretical issues-didactic lectures (28 schools), video material (27), small group discussion (26), handouts (23), case material based seminars (23), role play (16) and literature based seminars (8). All schools used at least three of these methods and two used all seven.

TABLE III Stated aims in teaching child psychiatry

\begin{tabular}{lc}
\hline Aim & $\begin{array}{c}\text { Number of schools } \\
\text { citing this aim }\end{array}$ \\
\hline
\end{tabular}

Teaching the recognition/classification of basic syndromes

23

Recognition of the importance of interactional factors

12

Knowledge of normal psychosocial development

Provision of interview skills

Treatment-Knowledge of options -Ability to provide some treatment

How and whom to refer

Exposure to multidisciplinary work

Impact of a child's illness on child and family

Knowledge of community services

Process of symptom formation. What is normal

Effects of disturbed/ill parents on children

Breaking bad news

Passing exams

Interesting a few students in a career in child psychiatry

11

10

5

7

6

4

2

1

1

1

Analysing data concerning topics taught was problematic. Some schools listed topics taught without indicating how much time was allocated to each, a few were unable to distinguish between theoretical and practical teaching, those that taught on multiple sites had different programmes on each site and one school had a programme which varied from firm to firm. A rough guide to the allocation of time available for teaching theory is given in Table IV where the amount of time allowed for a particular topic is expressed as a percentage of the total time allowed for all topics.

(e) Teaching practical skills. Nearly all schools claimed to pay attention to interview technique but only $13 / 28$ put aside specific time for practical training in interview skills. Mean time available was 2.6 hours. Two schools have decided that, given the limited time available, they will teach only theory. At three further schools not all of the students have a chance to observe clinical practice. Of the remaining 23 schools, only 13 provide observation of treatment as well as assessment. Most schools use a combination of one-way screens, closed circuit television and direct observation. 
TABLE IV

The teaching of theory: topics

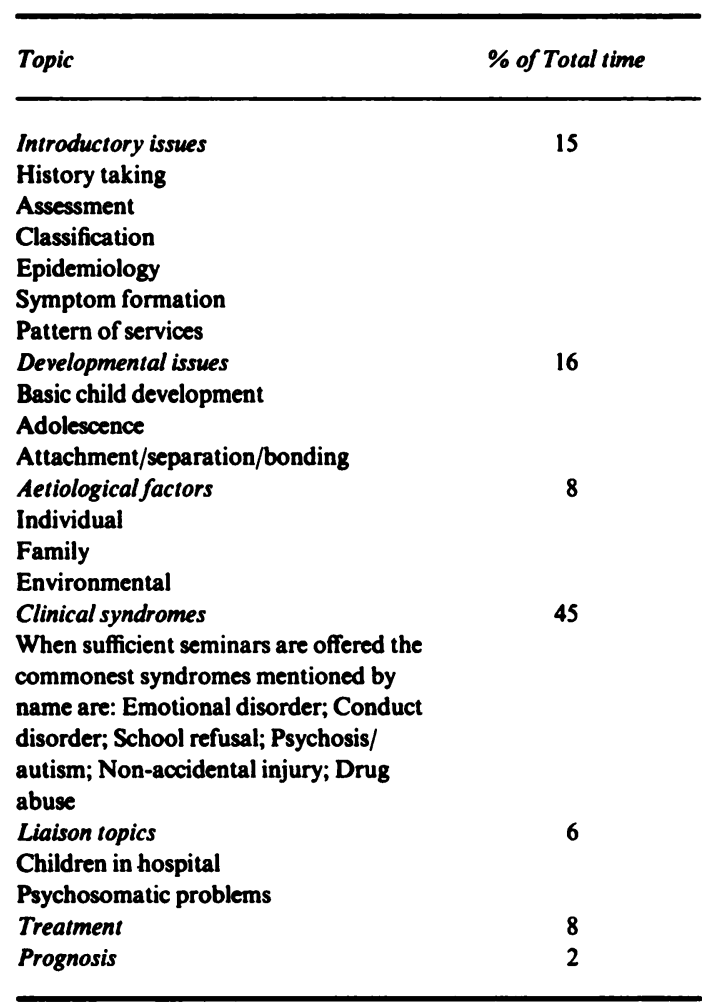

Only six schools allow student participation: at five, students participate in assessment by clerking cases and at one, students, as well as clerking, may join in co-therapy.

(f) Assessment. Eighteen schools formally assess their students at the end of the teaching. A variety of methods are used, e.g. MCQ, oral, clinical and written examinations or some combination of these. In 6/18 there are no consequences for failure at this assessment. In the other 12 schools the commonest consequence of failure is retaking the firm. It was generally unclear whether students were tested separately in child psychiatry or whether child psychiatry questions formed part of a wider test and if so how much of that test. Equally it was unclear if failure of the child psychiatry elements of, for example, an end of firm paediatric examination would entail the student retaking the whole firm.

At 18 schools child psychiatry questions may appear in final MB BS examinations (but not always). Only nine schools involve child psychiatrists as examiners in some capacity. There was no significant correlation between schools with large teaching programmes and an input to finals.
Twenty schools obtained regular feedback from students about their experiences of being taught and all but one had changed their course as a response to this feedback.

\section{Comment}

The figures presented here for overall time allocated to child psychiatry make sombre reading-it is difficult to envisage how the seven medical schools with less than 10 hours can do more than scratch the surface of the subject. In 1968 it was calculated that an average of 11 hours was devoted to child and adolescent psychiatry by the 18 schools which gave information (range 1-26 hours). ${ }^{1}$ By $1970^{2}$ the average time available had risen to 24 hours (range 8-67). Students today receive, on average, four hours less teaching than they did 16 years ago. Division of time available is also varied. The percentage allocated to teaching theory tended to rise as total hours fell-schools seemingly deciding that if little time is available it is better to teach some theory properly than to attempt theory and practice and fail at both.

There has been little change over the years in the setting of child and adolescent psychiatry teaching. Schools are still divided over whether paediatrics or adult psychiatry is the best place in the curriculum. The former allows more contact with children and families and thus more interview practice and possibilities of interaction with children. There are also more opportunities for teaching liaison work. Teaching within adult psychiatry has the advantage of sharing similar concepts of aetiology and management. It may be that teaching within both specialities, whilst creating problems of continuity, is the ideal arrangement. It should be noted that one or two schools also manage to have some small input to the obstetrics and gynaecology teaching.

Providing staff for teaching is still a difficult task. In 1968 there were no schools with a full time academic teacher in child and adolescent psychiatry. ${ }^{1}$ Russell ${ }^{2}$ reported three schools with academic staff and Shaffer, ${ }^{3}$ commenting on the heavy clinical load of most child and adolescent psychiatrists involved in teaching in London, recommended more academic staff be appointed. The current study found only nine schools with academic staff involved in teaching (four in London, five outside).

Whilst many of the problems of teaching child and adolescent psychiatry might be attributed to lack of time and staff, it is important to note that some schools seem able to organise their teaching to provide a lot of time with limited staff. It was clear that not all schools were using all the resources available to them in terms of manpower and in some the hours of teaching time seemed to be low in part due to a lack of motivation to increase them. Timetabling peculiarities often meant that what limited time there was available was not used effectively. The general impression on examining the completed questionnaires, with a few notable exceptions, is one of poor organisation and sometimes lack of interest. An example is the case of preclinical teaching. Most respondents did not answer the question on relevant preclinical content and seemed ignorant about 
possible links. Few of those that did answer had a clear idea of what was taught and at only one school were child psychiatrists involved in preclinical teaching. There was also much confusion as to what the purpose of teaching child and adolescent psychiatry to medical students was, with many schools having poorly formulated teaching aims. With regard to the lack of liaison between clinical and preclinical courses, it is of interest to note that nearly half the schools wanted to provide some knowledge of normal psychosocial development (Table III) but many were unaware whether this was covered in the preclinical curriculum).

Some schools had not made a distinction between theoretical and practical teaching, those who had gave, on average, nine hours to theoretical issues. A typical seminar programme would consist of one seminar each on introductory topics, aetiology, development and liaison, four seminars on clinical syndromes and one on treatment. There was enormous variation between schools concerning what should be covered, some schools teach topics which seem to reflect teachers' interests rather than students' needs (e.g. $20 \%$ of available time devoted to eating disorders of childhood at one school) and at least one school appears to vary its programme from firm to firm. Deciding on curriculum content is always difficult but should not be this haphazard. Shaffer et $\mathrm{al}^{3}$ recommended a good brief teaching syllabus and new methods of curriculum decisionmaking offer the possibility of basing decisions upon rational requirements. ${ }^{4}$

In only six schools are students allowed to participate in assessment and/or treatment. It would seem unlikely that more than a handful of schools are producing students with the practical ability to assess and manage simple child psychiatric problems.

Assessment of students is another area where teachers are unclear about current practice. Child and adolescent psychiatrists do not examine in final MB BS examinations in the majority of schools. Although questions on child and adolescent psychiatry may appear in finals at 18 schools, few respondents were clear about whether such questions appeared regularly, who set them or who marked them. A similar picture was found in the USA, with only $33 \%$ of schools giving grades or examining their students specifically in child and adolescent psychiatry. ${ }^{5}$ It is, however, an improvement on the situation found where only one UK school set finals questions and had child and adolescent psychiatrists as examiners. ${ }^{6}$ Babb and Gould, in recommending more child and adolescent psychiatry teaching, comment that "without questions in his exams he (the student) is actively discouraged in his studies".?

Whilst a few medical schools have produced adequate teaching programmes the general picture is of neglect and decay. Students receive less tuition now than they did 16 years ago, despite all the evidence which has accumulated over this period to confirm the importance of childhood psychiatric disorders in primary and paediatric health care planning. ${ }^{8-11}$ If this current situation is to be improved a number of changes will be needed:
1. Child and adolescent psychiatry departments must be more forceful in presenting their case for increased teaching time where this is inadequate.

2. More academic child and adolescent psychiatrists must be appointed with a clear brief to organise undergraduate teaching. This in itself will not necessarily increase teaching time but should allow courses to be better organised and a more efficient use made of existing time.

3. Agreement must be reached on what constitutes a core curriculum for medical students.

4. Clinical and preclinical teaching must be better integrated.

5. Decisions must be made about whether child and adolescent psychiatry teaching should provide students only with a knowledge of current specialist practice or with the ability to carry out simple therapeutic techniques in primary care and paediatric settings.

6. The examination of child and adolescent psychiatry in final examinations is essential.

\section{ACKNOWLEDGEMENTS}

I would like to thank all the child psychiatrists who co-operated with this survey by returning my lengthy questionnaires. In particular I would like to thank Dr Peter Hill for his support throughout the project and Mrs G. Rickard for secretarial assistance.

\section{REFERENCES}

${ }^{1}$ Carstairs, G. M., Walton, H. J., Smythite, J. R. \& Crisp, A. H. (1968) Survey of undergraduate psychiatric teaching in the United Kingdom (1966-1967). British Journal of Psychiatry. 114, 1411-1416.

${ }^{2}$ RusselL, J. A. O. (1970) Child psychiatry in the undergraduate medical curriculum. British Journal of Medical Education, 4, 305-311.

${ }^{3}$ Shaffer, D., Richman, N., Zeitun, H. \& Wolkind, S. (1979) A survey of child psychiatry departments in the teaching hospitals of the University of London. A Report by a Working Party to the Psychiatric Sub-Committee of the Board of Studies in Medicine. Unpublished.

4SPIVEY, B. E. (1971) A technique to determine curriculum content. Journal of Medical Education, 46, 269.

${ }^{5}$ Kivowitz, M. D. \& KAHN, V. (1976) The teaching of child psychiatry in US medical schools: Results of a survey. Journal of Medical Education, 51, 517-518.

${ }^{6}$ CAPES, M. \& KAHN, J. H. (1966) Child psychiatry in the United Kingdom. Acta Paedopsychiatrica, 33, 144-156.

7BABB, A.\& GouLD, J. (1968) The education of the medical student. In The Prevention of Damaging Stress in Children. Report of UK Study Group No. 1 to The World Federation for Mental Health (ed. J. Gould). London: Churchill.

BBalley, V., Graham, P. \& Boniface, D. (1978) How much child psychiatry does a general practitioner do? Journal of the Royal College of General Practitioners, 28, 621-626.

${ }^{9}$ CAMPION, P. D. \& GABRIEL, J. (1984) Child consultation patterns in general practice comparing 'high' and 'low' consulting families. British Medical Journal, 288, 1426-1428.

${ }^{10}$ GARRALDA, M. E. \& BAILEY, D. (1986) Children with psychiatric disorders in primary care. Journal of Child Psychology and Psychiatry, 27, 611-624.

${ }^{11}$ FItzGernLD, M. (1985) Behavioural deviance and maternal depressive symptoms in paediatric out-patients. Archives of Disease in Childhood, 60, 560-562. 